\title{
A importância das tecnologias numa perspectiva de inclusão digital para a prática docente
}

\section{The importance of technologies in a perspective of digital inclusion for teaching practice}

Eliane da Silva (elianeprof2017@gmail.com)

Universidade Atenas College University (EAD)

Adriano José de Oliveira (Adriano_oliveira71@yahoo.com)

Univerdade Atenas College University (EAD)

Diógenes José Gusmão Coutinho (gusmao.diogenes@gmail.com)

Universidade Federal de Pernambuco (UFPE)

\begin{abstract}
Resumo:Tecnologia é um termo muito utilizado ultimamente em todas as áreas do conhecimento, e principalmente na educação. Conceituada como um produto da ciência e da engenharia que envolve um conjunto de instrumentos, métodos e técnicas que visam à resolução de problemas e, além disso, é uma aplicação prática do conhecimento em diversas áreas de pesquisas humanas. Para isso, o trabalho tem como objetivo investigar a importância das tecnologias educacionais e a utilização desses recursos na implementação da prática docente em sala de aula. Diante da investigação, suscitou-se um problema sobre qual a utilização das tecnologias para a prática pedagógica do professor numa perspectiva de inclusão digital. A metodologia adotada é a pesquisa bibliográfica. Detroz et al (2015) define esse tipo de pesquisa como uma busca por referências teóricas, trabalhos relacionados ao tema e até mesmo ao estado da arte[...]. Desse modo o texto apresenta algumas definições sobre tecnologias, dos conceitos mais tradicionais até os mais atuais.Traz uma breve discussão sobre os desafios encontrados pelos professores ao utilizar essas novas ferramentas na sala de aula. Busca também uma reflexão sobre a relevância das novas ferramentas para o desenvolvimento da prática docente para a inclusão de uma sociedade digital.
\end{abstract}

Palavras-chave: Tecnologias Educacionais; Inclusão Digital; Prática e Prática docente.

Abstract: Technology is a term that has been used a lot lately in all areas of knowledge, and especially in education. Conceptualized as a product of science and engineering that involves a set of instruments, methods and techniques that aim to solve problems, in addition, it is a practical application of knowledge in several areas of human research. For this, the work aims to investigate the importance of educational technologies and the use of these resources in the implementation of teaching practice in the classroom. In view of the investigation, a problem arose about the use of technologies for the pedagogical practice of the teacher in a perspective of digital inclusion. The methodology adopted is bibliographic research. Detroz et al (2015) defines this type of research as a search for theoretical references, works related to the theme and even to the state of the art [...]. In this way, the text presents some definitions about technologies, from the most traditional concepts, to the most current ones. It brings a brief discussion about the challenges faced 
by teachers when using these new tools in the classroom. It also seeks a reflection on the relevance of new tools for the development of teaching practice for the inclusion of a digital society.

Keywords: Educational Technologies; Digital Inclusion; Teaching Practice and Practice.

\section{INTRODUÇÃO}

De acordo com os pesquisados, tecnologia é um produto da ciência e da engenharia que envolve um conjunto de instrumentos, métodos e técnicas que visam à resolução de problemas. É uma aplicação prática do conhecimento em diversas áreas de pesquisas humanas. Assim, no seu sentido etimológico, a palavra tecnologia tem sua origem no grego tekhne que significa técnica, arte, juntamente com o sufixo "logia" que significa "estudar" Sendo assim, o conceito de tecnologias tem a sua origem desde tempos antigos considerados primitivos. Conhecida como tecnologia primitiva clássica, que envolve as descobertas do fogo, a invenção da roda, a escrita, dentre outras.

Dessa forma, chega-se a uma conclusão de que a tecnologia é uma invenção humana, partindo das descobertas e observações por grupos de pessoas ou realizadas individualmente, com finalidades para atender a uma sociedade. A pesquisa tem como objetivos investigar por meio de leituras bibliográficas, sobre a importância das tecnologias para utilização e prática docente em sala de aula. Busca-se discutir sobre a necessidade de os professores estarem bem informados sobre o uso das novas tecnologias no contexto escolar ou em ambientes virtuais. Nesse sentido, o problema da pesquisa é sobre qual a utilização das tecnologias para a prática pedagógica do professor para uma inclusão digital.

De Vargas e De Araújo (2020) discorre no seu artigo sobre a construção de um novo paradigma educacional e sua relação com as tecnologias de informação e comunicação (TIC), fomenta que:

Desde sua evolução, o desenvolvimento tecnológico digital demonstra-se ser cada vez mais crescente em todas as circunstâncias da sociedade, de maneira mais didática e interativa na educação, tanto em termos de qualidade e quantidade quanto variedade (p.03).

Nesse sentido, o ensino da tecnologia é relevante para o contexto social dos indivíduos, uma vez que todos estejam envolvidos de forma parcial ou total no mercado de

${ }^{1}$ A Tecnologia, além dos conceitos mais tradicionais, também é conhecida como ferramenta, inovação tecnológica, máquina (WIKIPEDIA.COM.BR). 
trabalho. Desse modo pode-se apontar esta ferramenta como instrumento indispensável na execução das atividades realizadas pelos estudantes. Portanto, Bazzo e Pereira (2016) sinaliza que:

\begin{abstract}
Os professores devem incutir nos estudantes, além dos conhecimentos, a responsabilidade de refletir e trabalhar nesta área podendo dar suas repercussões de experiências dentro da sociedade. Nesse pensamento, pode-se afirmar que o uso da tecnologia demonstra certo interesse e serve de motivação para que os estudantes permaneçam envolvidos nos assuntos escolares (p.16).
\end{abstract}

Nesse envolvimento, o uso das tecnologias deve atuar de modo intenso, favorecendo aos alunos as possibilidades de se aprofundarem no mundo das ciências, buscando assim uma forma confiável e hábil na execução das atividades do cotidiano. Com o decorrer da leitura, distribuída em tópicos e subtópicos, os conceitos sobre tecnologias e inclusão digital terão uma compreensão mais abrangente. Dessa forma, o primeiro tópico aborda a metodologia da pesquisa e consequentemente o subtópico discute sobre a importância das tecnologias na prática docente. Desse modo, as discussões prosseguem enfatizando os desafios encontrados pelos professores ao utilizarem esses novos recursos ao se depararem com a realidade dos seus estudantes. E assim progressivamente percorrem os textos com suas diferentes absorções e concepções do uso das novas ferramentas para uma inclusão digital.

\title{
1. Metodologia
}

A referente pesquisa é de caráter bibliográfica e discute sobre as tecnologias e a sua utilização para a prática docente em sala de aula. Detroz et al (2015) define esse tipo de pesquisa como uma busca por referências teóricas, trabalhos relacionados ao tema e até mesmo ao estado da arte[...]. Procurando analisar os conceitos apresentados pelos autores Bazzo (2016); Gadotti (2012); Kenski (2015), dentre outros e quais recursos são oferecidos dentro das novas tecnologias, concepções de ensinos e funções dos instrumentos apresentados. Os jogos digitais, robótica e a prática inovadora do professor são fundamentais para um bom aprendizado na sala de aula e todo o contexto escolar.

Conforme Bazzo (2016), o professor precisa juntamente com seus educandos, navegar nos ambientes virtuais experimentais, que podem ser aqueles espaços físicos que a escola oferece. São espaços que alguns consideram como extras culturais, mas que estão 
inseridos nos parâmetros e propostas de ensino das esferas educacionais. Dessa forma, a aprendizagem acontece, os estudantes participam e se comunicam por esses espaços que os autores (TEIXEIRA,2017; MORAN,2014) denominam de cibercultura ${ }^{2}$, um espaço sistematizado dos conhecimentos, ideias técnicas e artefatos de padrões de comportamentos e atitudes de uma sociedade.

\section{A Tecnologia na sala de aula}

De acordo com estudos, tecnologias digitais é uma aplicação de um conhecimento científico ou técnico de um saber com o fazer. São métodos e materiais para a resolução de uma dificuldade. (CAVALCANTE, 2012). Partindo desses conceitos de tecnologias tradicionais, chega-se a uma compreensão que essa seria a parte física da comunicação. Sabendo que a parte da informação está relacionada à forma de determinar, gravar, armazenar, processar e reproduzir as informações.

Cavalcante (2012) comenta que a comunicação depende de outros suportes para que a informação aconteça. Um exemplo disso: os recursos mais simples como papéis, os arquivos, os catálogos, os HDs dos computadores, os $C D \mathrm{~s}, D V D \mathrm{~s}$, e atualmente os pens drives, os $m p 3, m p 4$ e outros. Quando se fala em novas tecnologias, não se diz respeito apenas às mais utilizadas recentemente, uma vez que as mais tradicionais foram relevantes nos processos de desenvolvimentos cognitivos e sociais dos educandos. Essa cognição acontece nos processos de codificação ${ }^{3}$ e decodificação ${ }^{4}$ que acontecem de acordo com a realidade e as histórias de vida, e as tradições e convivências de cada indivíduo. Nessas condições, acredita-se que as novas tecnologias da informação e da comunicação tenham um objetivo social, uma interação que, segundo Cavalcante (2012), permitem as trocas de dados dos seus usuários, permitindo alternativas e aberturas das mais diferentes informações.

De Vargas e De Araújo (2020) sinaliza que:

A informação constitui-se como parte integral da atividade do homem e, deste modo, todos os processos tocantes a sua existência, seja na esfera individual ou coletiva, se moldam por meio da tecnologia digital (p.07).

${ }^{2} \mathrm{O}$ espaço de sistematização dos saberes pode ser organizado no próprio ambiente escolar ou mesmo na sala de aula.

${ }^{3}$ Codificação é o processo de introdução de sinais ou códigos, mensagem de um texto elaborado.

${ }^{4}$ Decodificação: identificação, interpretação dos sinais, ou tradução de um código representado.

Recebido em: $30 / 04 / 2020$ 
Nessa concepção, as autoras citadas correlacionam que os avanços tecnológicos são partes integradora do processo evolutivo do homem que adquiriu um novo conceito a partir da inclusão digital. Com essa afirmativa, Cavalcante (2012) denota que nos dias de hoje os diferentes usos dessas novas tecnologias se confundem com as mudanças de padrões de trabalhos, do lazer, da educação, do tempo, da saúde e da própria indústria.

Conforme Cavalcante (2012), a verdade é que as novas tecnologias estão formando outro tipo de sociedade, novas atmosferas de trabalho, novos ambientes de aprendizagens e, podendo assim, criar um novo tipo de aluno que necessita de um novo tipo de professor. No entanto, alguns professores enfrentam novos desafios com o uso dessas novas ferramentas nos ambientes virtuais. Assim, o texto a seguir discute algumas relevâncias sobre esses desafios.

\section{Os desafios do professor com as novas tecnologias}

O uso das novas tecnologias é de fato uma temática bem relevante para a educação e todos os seus envolvidos. Porém, o que se torna mais intrigante é discutir sobre a execução da prática e as disponibilidades dos recursos apresentados.

De acordo com as pesquisas realizadas, os teóricos confirmam as hipóteses de que o grande desafio do professor incorporar essas ferramentas tecnológicas no processo de ensino aprendizagem é buscar a formação continuada, da mesma forma os mecanismos de troca e parcerias, na utilização das máquinas (BAZZO, 2016; CAVALCANTE, 2012; GADOTTI, 2012). Nesse sentido, compreende-se que os investimentos tecnológicos, não são eficientes para o desenvolvimento dos alunos sem uma formação para o professor, voltada para a utilização dessas novas tecnologias, e dessa forma não podem atender as expectativas de uma boa aprendizagem.

\subsection{Os ambientes virtuais experimentais}

Entende-se por ambientes experimentais, o espaço físico virtual que a escola pode oferecer para que seus estudantes percebam a universalidade de conhecimentos existentes na sua cidade. Um exemplo desses ambientes são os museus, os centros culturais, teatros, parques, ateliês, praças e outros. Esses ambientes virtuais precisam da mediação do 
professor, da colaboração dos estudantes, que podem organizar seus currículos com as atividades pesquisadas e com a participação da própria comunidade.

Moran (2014), fomenta que os espaços físicos virtuais são recursos de formação em tecnologias que contribuem para a formação docente, uma reflexão e ação, teoria e prática pedagógica, por meio das ferramentas apropriadas dentro desse ambiente. Esse espaço de aprendizagem virtual também é conhecido como cibercultura. A palavra cibercultura é um termo bem recente, porém vem acontecendo desde a década $1970^{5}$, podendo ser definido como um espaço sistematizado com conhecimentos, ideias, técnicas e artefatos "de padrões de comportamentos, atitudes que caracterizam uma determinada sociedade."

Para fomentar os conceitos de cibercultura, Teixeira (2017, p.01) comenta que: "aqueles que se dedicam ao estudo das práticas tecnicossociais da cultura contemporânea e de suas novas formas de sociabilidade foram comutadas do mundo físico para o universo virtual". Nesse sentido, o conceito de universo virtual é uma questão que está inserida no ciberespaço e pertence aos movimentos sociotecnocultural, inerente à mesma sociedade.

Lemos (2015) comenta que essas técnicas favorecem as condições para as interações e práticas sociais, que por sua vez, podem não representar uma cultura do ciberespaço, da incorporação no espaço virtual cognitivo das pessoas, na partilha dos sentimentos, informações e saberes. Lemos faz uma denotação que:

O ciberespaço possibilita o auto aprendizado, facilita a interatividade e estimula a troca de informações e saberes, mas não garante o sucesso do aprendizado, comumente desmotivado pela falta de estímulo. Disso decorre a importância da escola e do professor como mediadores do conhecimento a ser construído, aliados às estratégias pedagógicas, materiais didáticos e metodologias de ensino (p.01).

Nesse sentido, compreende-se que a utilização dessas tecnologias virtuais não se efetiva pedagogicamente sem a presença e a participação desse profissional na inserção das tecnologias educacionais e no espaço em sala de aula.

\section{3.2. As tecnologias no contexto escolar}

${ }^{5} \mathrm{O}$ conceito de cibercultura teria uma divisão da cultura contemporânea marcada pelo digital e o estudo das técnicas". Tecmundo.com.br (disponível desde 13/05/2010 por Luísa Barwinski).

Recebido em: $30 / 04 / 2020$

Aceito em: $23 / 12 / 2020$ 
Para que aconteça uma boa aprendizagem nesse processo tecnológico é necessário que haja uma boa relação educacional na utilização desses recursos. São questões que precisam ser articuladas de forma associada, voltada para a realização da sociedade, a qual os docentes estão inseridos. Para isso, esses conhecimentos deverão ser aproveitados no contexto escolar, favorecendo a esses indivíduos.

Com a utilização das tecnologias, faz sentido apontar que as dificuldades apresentadas, dar-se-iam, devido às ressocializações da realidade da própria sociedade inserida. Nesse sentido, todo e qualquer conhecimento que vir a contribuir para a educação, precisa ser direcionado para o contexto escolar desses indivíduos. Dessa forma, acredita-se que essas mudanças tecnológicas acabam sendo implementadas para uma conotação de que o fracasso e a repetência se dar por falta de motivação e da ausência dos recursos tecnológicos.

Silva et al (2019) comenta que esses novos recursos trariam um resultado mais eficaz no processo de ensino aprendizagem. No entanto, o que se deixa transparecer é que os docentes precisam mais de atitudes metodológicas para que as dificuldades sejam superadas, e não acabar comprometendo o potencial desses recursos na educação. No entanto, a utilização dos instrumentos tecnológicos na educação tem levantado bastante discussão, devido à implementação da informática no currículo educacional, oferecendo aos alunos a oportunidade de conhecer o mundo das tecnologias da informação e da comunicação.

Barros (2010), no seu artigo sobre as abordagens tecnológicas, faz o seguinte comentário:

Nas aulas, temos visto que os alunos utilizam programas específicos para escreverem textos, elaborarem listas e cálculos de suas despesas, organizarem agendas e fazem slides para apresentarem alguns trabalhos (p.02).

Nesse pensamento, Barros (2010) acredita que a utilização desses recursos de forma mais eficiente, seria mais adequada para se desenvolver e transformar a educação. Nesse sentido, os projetos de ensino aprendizagem se tornam significativos para os alunos perceberem a importância dessas novas tecnologias tanto no espaço educativo, quanto no 
convívio social desses educandos. Gadotti (2012) fomenta essa discussão sobre a importância das tecnologias para o ensino aprendizado na vida dos estudantes e para a sociedade.

Gadotti comenta que:

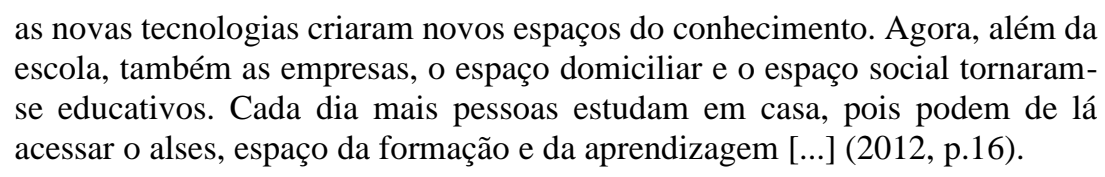

Nesse sentido, para alcançar esses conceitos e avanços das Tecnologias da Informação e Comunicação TIC, é que o sistema de ensino, tem oferecido por meio de políticas educacionais oportunidades para os estudantes e professores se apropriarem dessas novas ferramentas no seu ambiente de trabalho, na própria sala de aula.

Conforme Koch (2013, p.13), “as políticas educacionais influenciam o fazer pedagógico, considerando que vivemos numa época de globalização, tanto econômica, quanto tecnológica".

Koch sinaliza que os investimentos em tecnologias da educação podem acompanhar os avanços e trabalhar na diminuição das desigualdades existentes nas funções tecnológicas. Por esta razão toda comunidade escolar deve participar da inserção às novas tecnologias, para modificar e transformar a educação.

\section{Os jogos digitais e a prática do professor}

A utilização dos jogos digitais como recursos de aprendizagem, são fundamentais para o aprendizado dos estudantes. Uma vez que estes recursos são interessantes e atrativos para o seu cotidiano dentro e fora da sala de aula.

a. os jogos digitais

Os jogos digitais, além de desenvolverem o raciocínio lógico e habilidades cognitivas, promovem uma participação ativa, podendo assim ajudar na construção do conhecimento. Ribeiro (2010) sinaliza que os jogos na educação têm se tornado objetos de diversos estudos. Nessa concepção, ele faz o seguinte comentário: 
[...] O ensino de ciências e tecnologias, e especificamente o ensino de engenharia no Brasil, pode se beneficiar com a pesquisa sobre o potencial desse recurso, como apoio do processo educacional. Os jogos digitais, ao permitirem a assimilação em ambientes virtuais, proporcionam momentos ricos de exploração e controle dos elementos (RIBEIRO ET AL,2010).

Nesse sentido, todos os jogadores envolvidos podem utilizar esses jogos para explorar conceitos e, através de suas ações, encontrar significados para cada elemento conceitual, podendo assim vivenciar situações reais do cotidiano.

De acordo com Silva e Ramos (2018), essas questões de buscas realizadas pelos educandos podem facilitar ou dificultar o trabalho do professor, que em sua maioria ainda não tem afinidades com as novas tecnologias. Essa falta de afinidades denota a ausência de formações tecnológicas que impossibilitam o desenvolvimento desses recursos na prática em sala de aula.

Santana (2015) traz o seguinte comentário:

Há uma carência de capacitação dos educadores para incorporar estes instrumentos a suas atividades pedagógicas[...]. Nesse sentido, a utilização dos jogos quando vivenciados no espaço escolar são relevantes e levam os alunos a criar, a exercitar sua imaginação, produzir e a desenvolver o raciocínio lógico e estratégico para algumas situações $(2015$, p.04).

Rodrigues e Tenório (2015) fomenta que o professor pode encontrar simulações de jogos variados em algumas plataformas e, a partir da exploração de objetos ou/situações problemas, realizar / atividades com os estudantes. Nesse sentido, compreende-se que todas as habilidades desenvolvidas através dos jogos são essenciais para um bom desempenho dos estudantes nas atividades escolares. Da mesma forma, contribui para o aperfeiçoamento das relações como sujeitos participantes nos convívios sociais. 


\section{b. O uso da robótica}

A robótica, também conhecido como Lego, chegou no contexto escolar por meio das tecnologias da educação. Surgiu com o programa Robótica e Inovação Tecnológica lançado por meio de Decreto Municipal $n^{\circ}$ 27.699/2014, para todas as escolas da Rede Municipal (RECIFE,2015). Com o uso dessa tecnologia na educação, acredita-se que facilitará o processo de ensino-aprendizado dos estudantes, "podendo assim contemplar o desenvolvimento de dinâmicas mais lúdicas, auxiliar na demonstração e melhorar a compreensão dos conceitos [...]" (RECIFE, 2015, p.42). De acordo a proposta de ensino da rede sobre tecnologias educacionais:

A robótica é um recurso que permite ao estudante se enxergar naquilo que ele constrói, projeta-se através do objeto de sua criação [...], e a mediação do professor favorecerão à compreensão, à reflexão, à construção e à reconstrução do conhecimento (RECIFE,2015, p43).

Nessa concepção de construção e reconstrução do conhecimento, o lego é considerado "um brinquedo que garante o entretenimento para qualquer criança [...]" (RECIFE,2015, p.43). Assim, podendo ser usado como estratégia de ensino, contemplando todos os componentes curriculares, principalmente a matemática. Dessa forma, esse recurso educacional favorece o aprendizado dos conteúdos, desenvolvendo assim, habilidades de construção, raciocínio lógico, criatividades e inovações nos ambientes escolares e sociais dos estudantes.

Portanto, para que o processo de ensino-aprendizagem aconteça, deve ser passado para os estudantes que o lego é um recurso que vai contribuir para a compreensão e assimilação dos conteúdos apresentados na sala de aula e que não é simplesmente um brinquedo de montagem e construção. Ele exige participação, respeito e socialização de todos envolvidos. Nessa cooperação, o professor pode mediar esse aprendizado, favorecendo um momento reflexivo, construindo e reconstruindo esse conhecimento.

Conforme a proposta de ensino da Rede Municipal do Recife (2015), definese que:

Os princípios sobre os quais essa proposta se baseia, versam sobre a liberdade de aprender, ensinar, pesquisar e divulgar a cultura, o pensamento, a arte e o saber; a valorização do profissional da educação, assegurando-lhe formação 
adequada para o uso de todas as tecnologias robóticas[...],o reconhecimento da experiência extra escolar e dos conhecimentos prévios dos estudantes, a vinculação entre a educação escolar, o trabalho e as práticas sociais (RECIFE,2015,p.44).

Dessa forma, compreende-se que o uso da robótica na educação é uma proposta que objetiva a construção do conhecimento dos educandos de forma coletiva e individual, tornando professores e estudantes sujeitos coparticipantes das experiências e vivências do mesmo convívio social. Desse modo, essa cooperação e construção do conhecimento que acontecem por meio das tecnologias digitais são denominadas de inclusões digitais por uma pedagogia sustentável.

\section{Inclusões Digitais: uma pedagogia sustentável}

A palavra inclusão tem seus conceitos diversificados. E quando se trata de inclusão digital, o que vem à tona são conceitos de inserção às novas tecnologias. No entanto, precisa-se compreender que essa inclusão deve ter um sentido mais democrático para o ensino brasileiro e para a própria educação. Pischetola $(2015$, p.13) sinaliza que o conceito de inclusão digital "seria uma democratização do ensino das tecnologias da informação e comunicação".

Do ponto de vista da autora (PISCHETOLA,2015), assuntos sobre esse tema "têm repercutido no Brasil pelas dificuldades encontradas para a sua implantação" (p.13). Desse modo, acredita-se que a inclusão nesse ponto de vista de fato não existe. Sendo assim, a autora complementa que:

\footnotetext{
Somente colocar um computador nas mãos das pessoas ou vendê-lo a um preço menor, não é, definitivamente, inclusão digital. A inclusão acontece quando o indivíduo está inserido em um amplo processo de exercício de sua cidadania e não apenas quando ganha um computador ou tem acesso à internet (PISCHETOLA, 2015, p.04).
}

Dessa forma, os conceitos à inclusão digital precisam ser pensados e articulados nos aspectos sociais, culturais, intelectuais e também técnicos. Que segundo Pischetola (2015, p.04) estes fatores devem ser comunicados para todo o universo digital e 
educacional de qualidade ${ }^{6}$. Kenski (2015) sinaliza que as qualificações estão relacionadas as principais atividades representadas sócio, político, cultural e economicamente estão estruturadas cada vez mais em torno do nosso planeta, por meio da internet e de outras redes informatizadas. Nesse pensamento, Silva (2019) comenta que a escola e a própria educação devem traçar algumas estratégias para implementar e atrair assim os estudantes para os conhecimentos e recursos utilizados nos contextos pedagógicos.

Nessas condições, pode-se concordar com a autora que a inclusão digital pode ir além de um simples computador a uma pessoa ensinada e de alguns programas. É "preciso ensiná-las a navegar, se expressar, conversar, produzir e publicar suas produções" (PISCHETOLA, 2015, p.05). Entretanto, não fazer parte desse mundo digital configurase que todas as atividades estariam excluídas do processo de informatização, levando a economia e a cultura a sofrer gravemente e até mesmo a própria sociedade. Assim sendo, para que essa inclusão digital aconteça, a escola deve tornar esse espaço bastante atrativo para os estudantes. Dessa forma as tecnologias podem ser utilizadas para a melhoria do acesso às informações e à comunicação.

\section{CONCLUSÃO}

Os pesquisados sinalizam que a utilização das novas tecnologias no ambiente escolar constitui-se um fator relevante no aprendizado dos estudantes. E por esse motivo tem se tornado um instrumento de investigação para a prática dos professores em sala de aula. Essa busca pelo conhecimento ao utilizar os novos recursos, consequentemente leva o estudante para uma boa aprendizagem. Desse modo, o docente precisa se adequar às novas ferramentas para que a aprendizagem aconteça.

Foi observado a partir dos textos lidos que o grande desafio dos professores é a utilização das novas tecnologias como ferramenta de inclusão digital na prática pedagógica. Esse desafio, conforme foi elencado por alguns autores, decorre da falta de

${ }^{6}$ A inclusão digital também se caracteriza pela geração de empregos, pela transformação e melhorias de vidas, podendo assim capacitar os indivíduos profissionalmente, propiciando-lhes educação, cultura e cidadania para uma geração com direito às oportunidades. 
formação continuada para utilização das novas tecnologias que não acontece no cotidiano dos professores. Um fator preponderante é a falta de investimento em tecnologias, tornando assim insuficiente para o desenvolvimento de uma boa aprendizagem.

Conforme o desenvolvimento dos textos apresentados, os recursos tecnológicos existem no espaço escolar, porém não atendem às expectativas dos professores e tampouco às ansiedades dos estudantes que, por sua vez, já estão bem familiarizados com o uso das novas tecnologias digitais. Em decorrência disso, os pesquisados apontam que, para a utilização desses instrumentos e um bom aproveitamento em sala de aula, os jogos digitais seriam um bom recurso a ser indicados para a realização das atividades rotineiras dos professores. Nesse sentido, a robótica, por exemplo, permite ao estudante construir conceitos e por meio desses instrumentos, se projetarem e, ao mesmo tempo, tornandoos objetos de sua criação. Pois acreditam que são fundamentais para o aprendizado dos educandos, uma vez que desenvolvem habilidades de cooperação, respeito às regras e aos convívios sociais.

Enfim, as novas tecnologias não apenas desenvolvem as habilidades motoras e de raciocínio lógico, mas também viabilizam seus usuários para a vida em sociedade, numa forma de diálogo, da participação e da interação do outro, tornando-se sujeitos do processo de construção do conhecimento, formando assim uma pedagogia sustentável. Portanto, os conceitos de tecnologias sustentáveis ${ }^{7}$ para uma inclusão digital, podem ser compreendidos como ações voltadas para os conhecimentos pedagógicos desenvolvidos e compartilhados dentro e fora da sala de aula. Desse modo, as ferramentas tecnológicas se tornam mais significativas e eficientes quando utilizadas para a construção e desenvolvimento de habilidades socioeducacionais dos educandos.

\section{REFERÊNCIAS}

\footnotetext{
${ }^{7}$ Tecnologia sustentável: Processo de democratização do acesso às tecnologias da informação, de forma a permitir a inserção de todos na sociedade da informação. (pt.wikipédia.org>wiki>inclusão digital).
}

Recebido em: $30 / 04 / 2020$ 
BARROS, Jussara de. Educação e Recursos Tecnológicos. 2010. Disponível em $<$ https://cesmac.edu.br/admin/wp-content/uploads/2014/11/a-cibercultura-naeducacao.pdf>

BARROS, Maria L'Amour Barreto de Élia de Fátima Lopes Maçaira e Katia Marcelina de Souza. Política de ensino: tecnologias na educação. Recife: Secretaria de Educação. 2015 .

BAZZO, Walter Antônio e Luiz Teixeira do Vale Pereira. Introdução à engenharia: conceitos, ferramentas e comportamentos. Florianópolis: Editora UFSC. 2016.

CAVAlCANTE, Márcio Balbino. A Educação Frente às Novas Tecnologias: Perspectivas e Desafios. São Paulo: Profala, 2012. Disponível em <https://www.profala.com/arteducesp149.htm (consultado em 06 de junho de 2019)>.

DETROZ, Juliana Patrícia; HINZ, Mauro; DA SILVA HOUNSELL, Marcelo. Uso de Pesquisa Bibliográfica em Informática na Educacão: um Mapeamento Sistemático. Revista Brasileira de Informática na Educação, v. 23, n. 01, p. 28, 2015.

DE VARGAS, Rosana Souza; DE ARAÚJO, Maria Cristina Pansera. A construção de um novo paradigma educacional e sua relação com as tecnologias de informação e comunicação. Revista Insignare Scientia-RIS, v. 3, n. 1, p. 235-256, 2020.

GADOTTI, Moacir. A Boniteza de um Sonho: ensinar-e-aprender com sentido. São Paulo: Editora e Livraria Instituto Paulo Freire. 2012.

KENSKI, Vani Moreira. O Ensino e os Recursos Didáticos em uma Sociedade cheia de Tecnologias. Campinas: Papirus. 2015.

$\mathrm{KOCH}$, Marlene Zimmermann. As tecnologias no cotidiano escolar: uma ferramenta facilitadora no processo ensino-aprendizagem. 2013. Disponível em <https://repositorio.ufsm.br/handle/1/498>

LEMOS, André e Perl, Lara. " Comunicação e Tecnologia: Uma experiência de Classe Invertida". Comunicação e Educação Vol:20 (2015):127-139.

MORAN, José Manuel, Marcos T. Masetto, Marilda Aparecida Behrens. Novas Tecnologias e Mediações Pedagógicas. Campinas: Papirus. 2014 
PISCHETOLA, Magda. "Tecnologias em sala de aula: contribuições para uma pedagogia sustentável". Anais da 37a Reunião científica da ANPEd. (2015).

RAMOS, K. et al. Jogos digitais, habilidades cognitivas e motivação: percepção das crianças no contexto escolar. Simpósio Brasileiro de Games e Entretenimento Digital, v. 17, 2018.

RIBEIRO, Luis Otoni Meireles et al. "Modificações em jogos digitais e seu uso potencial como tecnologia educacional para o ensino de engenharia", Revista Novas Tecnologias na Educação Vol: 4 (2010): a36_21203.

SANTANA, Mariana Galdino, et al. "JOGOS DIGITAIS: BRINCADEIRA OU AUXÍlIO PEDAGÓGICO?" Anais do Congresso de Inovação Pedagógica em Arapiraca. Vol. 1. No. 1. 2015.

SILVA, Eliane da; Oliveira, Adriano José de E Coutinho, Diógenes José Gusmão. "Formação de professores em tecnologias: reflexões sobre a prática". Revista Científica Multidisciplinar Núcleo do Conhecimento Vol:10 (2019): 36-44.

TENÓRIO, André, Fabiana Oliveira da Silva Rodrigues, and. Thaís Tenório. "Jogos e simulações digitais na prática de ensino de professores de matemática." Revista de Educação, Ciências e Matemática 5.3 (2015).

TEIXEIRA, Marcelo Mendonça. A influência da Cibercultura na era atual. 2017. Disponível em<https://cesmac.edu.br/admin/wp-content/uploads/2014/11/acibercultura-na-educacao.pdf $>$. 